\title{
The Syntactic Properties of Negatives
}

\author{
Mohammad Ali Al Zahrani \\ Taif University, Taif, Saudi Arabia
}

\begin{abstract}
This paper aims at describing the syntactic properties of the Hijazi Arabic negative particles. It presents the basic hierarchy within which the negatives under study occur. It then shows the properties of the Hijazi Arabic negatives and that they project a NegP that has scope over the proposition. It scopes over perfective, imperfective verb forms. It also modifies non-verbal clauses. Thus, NegP may select for a verbal or non-verbal predicate according to the negative element generated in NegP. The NegP interacts with the functional categories (TP, AspP, Tax-AspP, and $\mathrm{VP} /$ PredP) and this interaction is witnessed in the incorporation process that takes place in NegP.

Keywords: Arabic, negatives, syntax, projection, incorporation
\end{abstract}

\section{Introduction}

This paper aims at describing the syntactic properties of the Hijazi Arabic (HA, henceforth) negative particles. It shows their projections, their variable scope, and how they interact with other functional categories. The significance of this paper springs from the fact that the research on HA, in general, and on negatives, in particular, is very minimal. To the best of the author's knowledge, HA negatives have been slightly addressed in an old descriptive work by Sieny (1978) and in a recent study by Al Zahrani (2008). Sieny (1978) generally and traditionally describes some of the main aspects of HA grammar. Yet, negatives were not his main focus as they were just introduced in a few examples without an in-depth analysis. Al Zahrani (2008) focuses on the morphological impact of the negatives on both Standard Arabic and Hijazi Arabic. Yet, the syntactic description has not been thoroughly investigated. Therefore, this paper aims at filling this gap by exploring the syntactic properties of the negative particles in HA. It explores their syntactic placement and shows that the scope of negation differs depending on the position of the negative particle as well as the negated element. This paper will not investigate the slightly different semantic interpretations of the negatives resulted by their different scopes as this needs a heavy corpus and will take the reader too part afield.

The organization of this paper is as follows. The next section sheds some light on the location and significance of Hijaz. Then a section follows to briefly show the theoretical background that presents the syntactic framework which will be used for the analysis of the syntactic properties of a set of HA negatives which constitute the focus of this study. Other sections follow to state some of the properties of the HA negative particles, and show the negatives in verbal clauses and how the incorporation process takes place in the head of NegP. Then the paper describes the negatives in non-verbal clauses and sets out the conclusions and recommendations.

Mohammad Ali Al Zahrani, assistant professor, Ph.D., Department of Foreign Languages, Taif University. 


\section{Location and Significance of Hijaz}

The significance of the Hijaz cities reflects the significance of HA. There are four main cities in the region of Hijaz. These main cities include Taif and Jeddah, which are the only ports giving access to the holy city of Makkahby air or by land. Taif is known as the most attractive summer resort not only for Saudi and non-Saudi residents of the Kingdom, but also for people from neighboring countries. It is also known across the Arabian Gulf for its summer fruits. Jeddah is one of the largest commercial cities in the Kingdom of Saudi Arabia. Other important cities include the religious centers of Makkah and Madinah. Muslims from all over the world consider these two cities to be the most sacred cities due to the existence of the Two Holy Mosques. Millions of Muslims from the entire world visit these two holy mosques every year. Some of them spend months in Makkah and Madinah before they go back to their homes. This further enhances the historical and religious importance of the Hijaz province. Al-Barakati (1984) claims that all historians agree upon that the gathering of Muslims in Makkah and Madinah makes the Hijazi dialect known to the majority of visitors due to the fact that they accommodate themselves to the Hijazi dialects.

Although the historical location of Hijaz has long been hotly debated by Arab scholars, it is agreed nowadays that the Hijaz area is "the region between Bishah, from the southeast, and Alleath from the southwest, to the north where [Madinah] is located. This is the so called 'Hijaz' including all Hijaz cities" (Al-Barakati, 1984, p. 21). The Arabic word Hijaz literally means "the barrier". It is a noun derived from the verbal root $\sqrt{ } \mathrm{HJZ}$ whose perfective verb form hajaza means "to border/to make a barrier". The Hijaz region has been given such a name because of its geographical location, a "boundary between Najd and Tihamah" (Ibn Qutaibah, 1970, p. 181). See Figure 1.

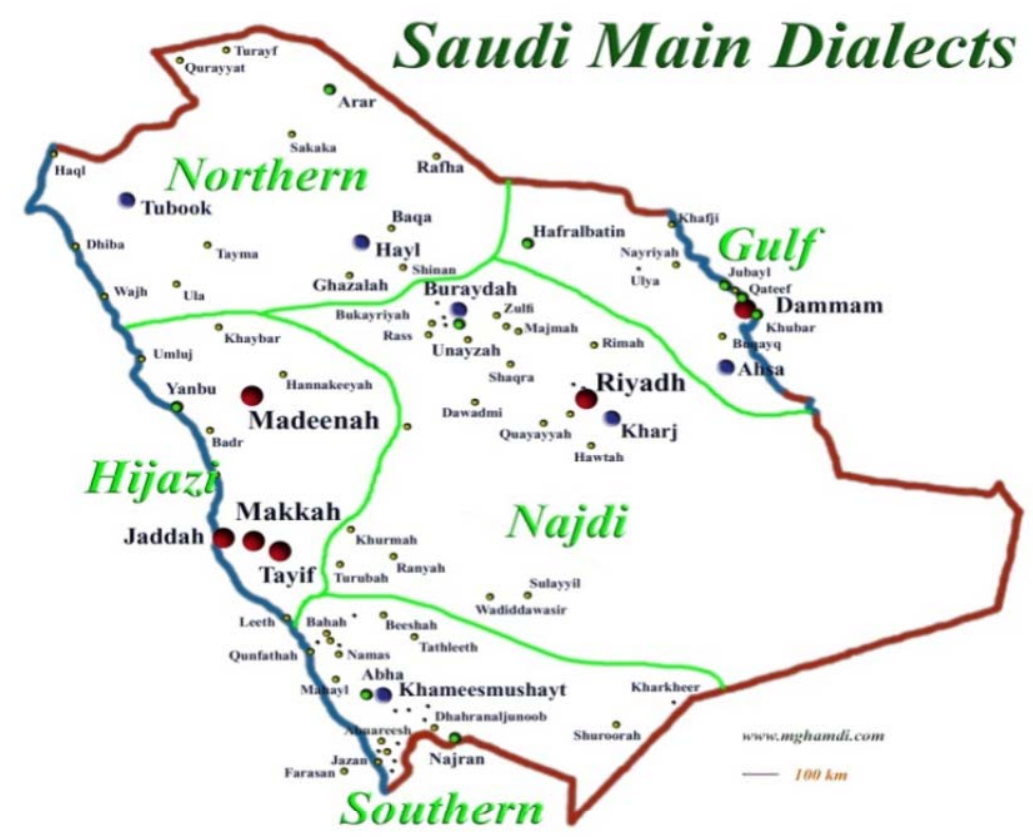

Figure 1. Saudi main dialects. Adapted from Masanori, 1992.

The kingdom of Saudi Arabia has three major groups of dialects which are all descended from Classical Arabic. They include Najdi, Shargi, and Hijazi. Najdi Arabic is spoken in the north central part of Saudi Arabia while Shargi, which means eastern, is the dialect spoken by people of the eastern and northern provinces 
(Margaret, 1975). While HA is spoken in the western region that includes the main four urban cities of Makkah, Madinah, Taif, and Jeddah, it is also "used throughout the country for government and commercial purposes, and has become the most widely-understood dialect in the Arabian Peninsula" (Margaret, 1975, p. v). The population of the Hijaz area is roughly 7.7 million, according to the Demographic Survey (2007, p. 45) of the Ministry of Economy and Planning. ${ }^{1}$

Hijazi people use both Modern Standard Arabic (MSA) and Hijazi Arabic. The crucial difference between the two varieties is the overt case and mood marking system of MSA. HA lacks such a morphological marking system. While HA is the daily spoken variety, MSA is considered to be the official language used by educated people in books, newspapers, news broadcasts, periodicals, official documents, formal speeches, street signs, and religious ceremonies, including the weekly Friday's ceremony.

\section{Data and Questions}

The description of the HA negatives is primarily based on the native judgement of the author, his family, and a number of other participants. This paper aims at describing the HA negative particles and it addresses the following questions. What are the HA negatives? Where are they projected? What is their scope? What other functional categories do they interact with?

Consider the examples in (1).

\begin{tabular}{cccl} 
(1) a. maa & y-Thaakir & Anas & druus-uh \\
NEG & IMPF.3SG.M-study Anas & lessons-N.3SG.M \\
"Anas does/is not study/studying his lessons." & \\
b. maa & Thaakar & Anas & druus-uh \\
NEG & PF.study-3SG.M Anas & lessons-N.3SG.M \\
"Anas did/has not study/studied his lessons." & \\
c. Anas & muu & fi & al-bait \\
Anas & NEG & PREP & DET-house \\
"Anasis not home." & \multicolumn{4}{l}{} \\
d. *maa & Anas & druus-uh \\
NEG & Anas & lessons-N.3SG.M \\
e. *maa & Anas & fi & al-bait \\
NEG & Anas & PREP & DET-house
\end{tabular}

The examples in (1a-c) show the HA negatives maa and muи and that maa is followed by perfective and imperfective verb forms while тии is not. Also the ungrammatical examples in (1d-e) show that the negative maa cannot be immediately followed by the DP Anas. To account for these properties and show the syntactic placement of the negatives, the paper should briefly present, in the next section the basic hierarchical clausal structure within which the negatives under study occur.

\section{Theoretical Background}

In this study, the author adopts the well-presented and argued hierarchical structure presented by $\mathrm{Al}$ Zahrani (2013) who has adopted Bahloul's $(1994,2008)$ insights of Tax-AspP. The adopted theories provide an explanatory framework that allows a straightforward account of the relevant facts. The paper will briefly present the HA basic syntactic structure, however, the reader is advised to see Al Zahrani (2013) for further detail.

1 The report can be found on line on http://www.cdsi.gov.sa/english/. 
HA has two main types of declarative clauses. The first type includes verbless clauses which lack a verbal predicate and whose time reference is present. These are also known as non-verbal clauses or nominal clauses. The second type includes those which have verbal predicates, and are therefore called "verbal clauses". Negative particles occur in both clauses and the negative projections interact with the other functional projections that are contained with the TP clausal structure. In verbal clauses, the negatives integrate into the basic hierarchical structure TP, AspP, Tax-AspP, and VP. They also modify nominal clauses (i.e., verbless clauses) whose basic structure is TP, AspP, and a non-verbal PredP. The head of TP hosts the abstract [+past] or, by default, non-past tense features. While [+past] is always marked, either by the auxiliary kaan that is base-generated in $\mathrm{T}^{\mathrm{o}}$, or by another verb (lexical or functional) form, non-past is always unmarked. AspP is found in all clause types and it is the base-generation position of the imperfective auxiliary ykuun.

Adopting Bahloul's $(1994,2008)$ approach to Arabic verbs, the author assumes a Taxis-Aspect functional category into which HA lexical verbs $\mathrm{C}$-commanded by $\mathrm{T}^{\circ}$ must raise. This position is distinct from the higher $\mathrm{Asp}^{\circ}$. Tax-AspP only occurs in verbal clauses containing lexical verbs, which move from $\mathrm{V}$ to Tax-AspP to check their Taxis-Aspect features. HA verbs inflect for aspect: perfective and imperfective. These verb forms may denote past, present, or future events relative to the time of the speech act, as well as taxis which pertains to the relative time of (sub)events, and aspectual properties, completed or uncompleted event, bounded or unbounded event. The time references are not marked morphologically on verbs but are derived from a combination of the aspectual marking on verb forms and their syntactic relationship to functional categories: Tense $\left(\mathrm{T}^{\circ}\right)$ for event time relative to utterance time, and $\mathrm{Tax}-\mathrm{Asp}^{\circ}$ for relative time of (sub)events. These two positions are the only ones which may be overtly occupied by a perfective verb. The VP shell includes both the lexical verbal root, which must move to Tax-AspP to merge with taxis-aspect features, and the internal arguments of the verb. In verbless clauses, the PredP contains the subject DP and the non-verbal predicate.

The paper briefly shows some of the basic hierarchical principles for this paper. The X-bar theory has provided the means to represent constituents of the items from the lexicon when undergoing some syntactic operations. That is, the syntactic constituents are built up using the rules of the X-bar theory such that each phrase has a head (X) a complement (YP), and specifier (ZP) as represented in Figure 2.

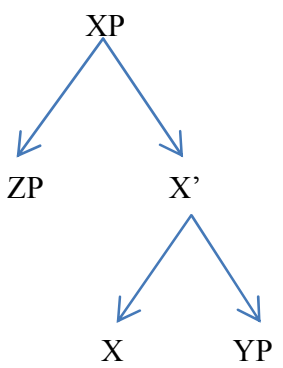

Figure 2. Phrase structure. Adapted from Chomsky, 1994, p. 172.

$\mathrm{XP}$ is the maximal projection of a phrase that contains the specifier (ZP). "Specifiers are sisters to an intermediate X-bar projection, whereas complements are sisters to a head" (Radford, 1997a, p. 92). The maximal projection also contains the intermediate projection ( $\left.\mathrm{X}^{\prime}\right)$, which contains a head $(\mathrm{X})$ and a complement (YP). (XP) and (X') are of the same category as the head (X). For instance, if the head (X) is a verb, this means $(\mathrm{XP})$ is a VP and ( $\left.\mathrm{X}^{\prime}\right)$ is $\mathrm{V}^{\prime}$ ( $\mathrm{V}$-bar).

The "o" notation is used for the head (or minimal projection of a category), so the $\mathrm{T}^{\circ}$ is the head of TP. 
While the author assumes the presence of these functional categories, he rejects AgrP, following Chomsky (1995), and treat it as a morphologically marked relationship between features of the Subject DP and inflecting functional categories. Chomsky points out that at the semantic interface the agreement heads cannot be assigned any interpretation and this leads the derivation to crash. Hence, Chomsky (1995) concludes that "it seems reasonable to conjecture that Agr does not exist" (p. 377). The rejection of agreement heads (AgrP) has been favored in the most recent Arabic literature including the work of Benmamoun (2000), Aoun, Choueiri, and Benmamoun (2010), and Fassi (2012).

The author adopts "The Internal Subject Hypothesis" advocated by Speas (1986), Mohammad (1989), and Koopman and Sportiche (1991) according to which the Subject argument of a verbal predicate is not generated in INFL, but is base-generated as the Specifier of the predicate's head: within the thematic VP shell. Following the schema in Figure 2, the VP has the structure shown in Figure 3 in which the Subject is generated in the Specifier position.

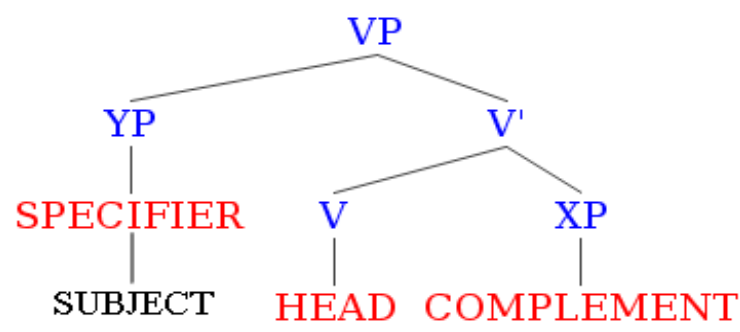

Figure 3. Basic VP constituent.

The author assumes this type of structure for all phrasal categories, and calls the subject generated in Spec,VP a DP Subject (Determiner Phrase), because it is assumed that every NP is dominated by a DP, following Szabolcsi (1983), Abney (1987) and subsequent work.

The basic hierarchy of P\&P can incorporate the distinction between vP and VP in the Chomskyan literature, including work within the Minimalist framework. The literature shows that VPs have a complex structure forming an inner VP, which is dominated by the outer vP. Some arguments, e.g., agent, originate in Specifier of vP while others, e.g., theme, originate in Specifier of VP (Spec,VP, henceforth) (see, for example Radford, 1997a, 1997b). Little "v" is typically equated with "cause" hence the head of a transitive verb phrase: [VP [VP]] where VP is governed by " $\mathrm{v}$ ". However, because this distinction is not pertinent to the focus in this paper, the author presents a simplified structure in which the VP shell equates with either the little vP, or VP. None of the negative elements investigated in this study distinguishes the inner structure of the predicate phrase where the lexical verb is base-generated.

Each of the functional projections that will be assumed in this work (TP, AspP, ModP, NegP, etc.) has a specifier to which the subject DP can move from its position in (Spec,VP), if it is not blocked from doing so.

This extended P\&P approach provides a theoretical framework for the analysis of the data where the author shows that these multiple functional projections do play different syntactic roles and that they all interact in the clausal structure in a manner conforming with the constraints imposed by this framework on the nature of XP structure, on head and phrasal movement (incorporating insights of Travis (1984) and others) and the role of feature checking. The analysis of negatives shows how they interact with the other functional categories which are hierarchically organized and with their features. The paper will assume that the hierarchical relationship between Tense and Aspect is constant, one in which $\mathrm{T}^{\circ}$ always C-commands Aspect, while a 
category such as NegP may occupy a limited range of positions that directly reflect certain of their semantic properties.

Another feature of the P\&P framework (and the later Minimalist Program) is the modular architecture of the grammar. As will become apparent, the author assumes a level of overt syntactic structure that is reflected in the phonological form and also an abstract level of Logical Form where syntactic operations may apply which are more indirectly reflected in the phonological form. This paper will argue that while the Subject DP may occupy a range of Specifier positions in a clause where it is assigned Nominative case, there is obligatory covert movement of the Subject at LF (Logical Form: "a structure level at which representations include only semantic features" (Radford, 1997a, p. 264) to the Spec,TP. This contrasts with the obligatory overt movement of the Subject to Spec,TP in clauses headed by the Complementizer inn which assigns Accusative case. The modular architecture of the grammar is central to the analysis of the relationship between the scope of negation and the syntactic properties of the negative heads under investigation in this study; the paper will show how the scope of negatives is directly reflected in their different syntactic behaviors.

Now the paper sheds light on the syntactic operation that involves both "Merge" and "Move" by which a Head adjoins to another higher Head. What is needed in the analysis is the so-called head-to-head movement. In the author's model, because Arabic verbs are composed of roots (radicals), the verbal root is base-generated in the head of VP, i.e., $V^{\circ}$. The root must undergo the Move and Merge syntactic operations to check the features of the higher head of a projection which the author calls "Tax-AspP", as in Figure 4.

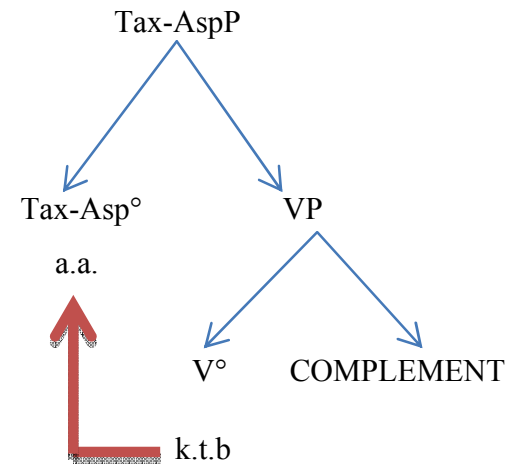

Figure 4. Head-to-head movement.

As the Arabic verbal root and inflectional morphology are bound morphemes, the morphological features of HA verbs require roots to move from the head $\mathrm{V}^{\circ}$ to the head Asp ${ }^{\circ}$ to check off the verb's aspectual features. Hence, the root $\sqrt{ }$ k.t.b must move and interlock (merge) with a vocalic melody [a.a] to derive the perfective aspect verb katab "he wrote/has written". Notice that the elements of both the root and the vocalic melody are discontinuous after their merger in $A^{\circ}{ }^{\circ}$. Kremers $(2003$, p. 46) calls the merger between the morphological elements of the heads "head merger": a merger where the elements of the two heads are continuous. This Head-to-Head movement is overt (before spellout) and is reflected (from the merge between the heads) in the phonetic form "katab". What this paper calls "Merge" here does not form a new projection, i.e., the same level of the AspP projection is maintained wherein the verbal root (in $\mathrm{V}^{\circ}$ ) and the vocalic melody (in $\mathrm{Asp}^{\circ}$ ) merge. Al Zahrani (2013) has demonstrated that it is not only aspect (completeness/boundedness) but also taxis (event time, time of one event or situation relative to another) which are essential specifications of every HA verb that are realized morphologically by contrasting verb forms. 
More importantly, this paper shows how some other syntactic elements may move from their projections (Heads) into the NegP projection: a movement by which an element head-adjoins to the negative element in $\mathrm{Neg}^{\circ}$ and forms an inseparable complex. This paper calls this movement "incorporation" where one head is incorporated into (or adjoined to) another head.

Contrary to the overt movement discussed above, there is covert movement that happens at LF level (LF movement). The analysis invokes the LF movement to account for the Subject agreement and Subject case facts. Case Theory argues that all overt DPs must have case (Chomsky, 1980). In more recent work Chomsky (1995) has argued that "the case systems are basically similar cross-linguistically and the differences lie primarily in their phonetic realization (the mapping to PF)" (p. 26). Although case is not morphologically realized in HA, except in the pronominal paradigm, the author argues that Nominative case is assigned by $\mathrm{T}^{\circ}$ to the $\mathrm{DP}$ even where the latter is in its base position in Spec,VP, since the DP does not have to overtly move to Spec, TP, since Nominative case behaves like a "weak" feature. This feature is checked in LF by covert movement of the Subject DP to the Spec,TP position where Nominative case is assigned. This covert movement forms a TP > VP chain, makes TP the locus of Agreement, and assigns nominative to the chain down to DP that does not have to overtly move. The surface marking of this chain corresponds with the overt marking of Subject features (person, number, gender) on all verbs within the chain; there is concordial Subject agreement marking in HA. This LF movement is restricted to nominative case assignment where the TP is not dominated by a CP headed by complementizer inn. The presence of such a CP forces the DP to overtly move to Spec,TP where it is assigned accusative.

Where there is no overt subject DP, i.e., only features associated with the subject, such as gender, number, which are reflected in subject agreement, the author argues that Nominative case is assigned to the Subject pro that is in Spec,TP. Notice that Spec,TP can be empty in the sense that no thematic constituent or features occupy that position. Thus, pro which is associated with Subject features contrasts with the absence of features. This absence of features is reflected in the form of the verbs within the TP, which is the unmarked form that is also used with third person singular, masculine Subjects. Similarly, assigning Nominative case in nominal clauses as well as the inflection of the Subject features (person, number, gender) take place through the TP > PredP chain.

This discussion illustrates the basic HA syntactic hierarchy for verbal clauses (Figure 5), where TP dominates AspP, and roots move from VP to Tax-AspP which is dominated by AspP; it also illustrates the basic hierarchy for nominal clauses (Figure 6) where TP dominates AspP that dominates PredP.

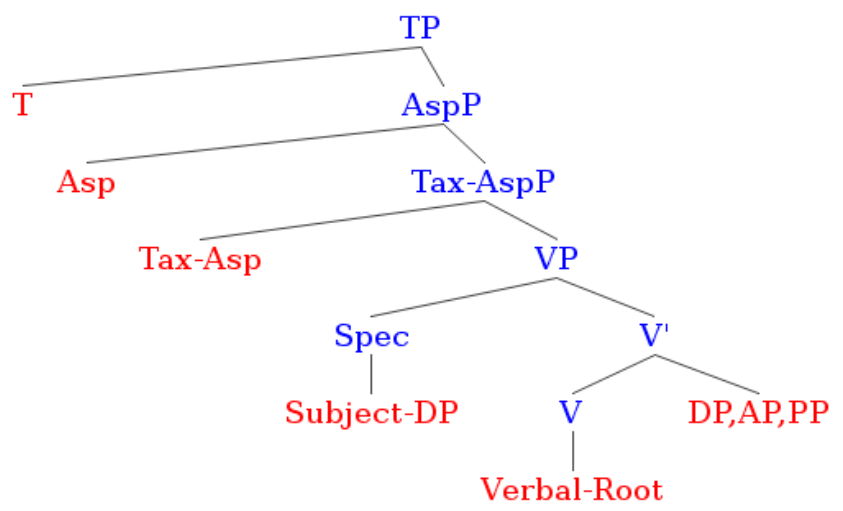

Figure 5. Basic hierarchy for verbal clauses. 


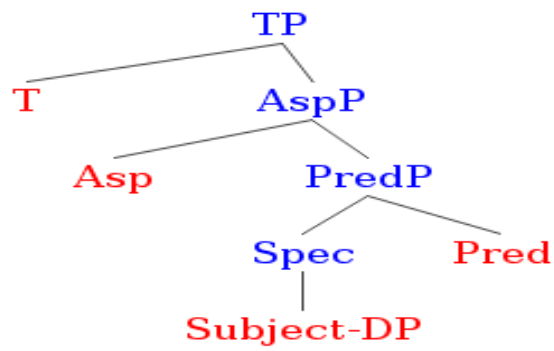

Figure 6. Basic hierarchy for nominal (non-verbal) clauses.

The only difference between these two diagrams is that verbal clauses contain the heads Tax-AspP and VP whereas nominal clauses contain the head PredP. The author shows that negative particles project higher or lower than the functional/lexical projections of TP, AspP, Tax-AspP, and PredP. Now the paper shows the general properties of negatives.

\section{Negative Particles: Properties and Projection}

According to Al Zahrani (2008), HA has two basic negative particles, namely laa and maa where the latter has the two gender-based variants тии (masculine) and mеe (feminine). However, while the negative mee still retains its gender properties and can only be used with feminine predicates, the negative muи has lost its gender distinction properties and, thus, can be used with masculine and feminine predicates (Al Zahrani, 2008).

Briefly, the negative laa may function either as a prohibitive particle that, for such negation, must always subcategorize for an imperfective verb form only; or as a negative particle in correlative structures laawalaa "neither...nor" where it may be followed by a perfective or imperfective verb form (for examples on this see Al Zahrani, 2008). In contrast, the negative maa is often used before perfective or imperfective verb forms. What is common between these two negatives is that they are the only available negatives for verb forms. Contrary to that, the gender-based negative variants тии and mee are never used with verb forms but with all other nominal forms though they are variants of maa that almost always subcategorizes for finite clauses (Al Zahrani, 2008).

The author argues that both HA basic negatives and the variants of maa are heads. These negatives project in NegP that can be lower or higher than TP as shown in the next sections. There are at least two reasons that demonstrate that HA negatives show properties of heads. First, HA basic negatives maa and laa (when the latter does not function prohibitively) may host subject clitics and this is a property of heads as is shown in the following paradigm (see Table 1). The author will show in the next section that this hosting is resulted from the Move \& Merge (or incorporation) between the head of negation and its immediate following head in $\mathrm{Neg}^{\circ}$.

Table 1

Negatives laa and maa May Host Subject Clitics

\begin{tabular}{|l|l|l|l|}
\hline NEG + SUBJ CLITIC & Form & NEG + SUBJ CLITIC & Form \\
\hline NEG + 1SG & laani & NEG + 1SG & maani \\
\hline NEG + 1PL & laHna & NEG + 1PL & maHna \\
\hline NEG + 2SG.MASC & lantah & NEG + 2SG.MASC & mantah \\
\hline NEG + 2SG.FEM & lanti & NEG + 2SG.FEM & manti \\
\hline NEG + 2PL & lantum & NEG + 2PL & mantum \\
\hline NEG + 3SG.MASC & laahu & NEG + 3SG.MASC & maahu \\
\hline NEG + 3SG.FEM & laahii & NEG + 3SG.FEM & maahii \\
\hline NEG + 3PL & laahum & NEG + 3PL & maahum \\
\hline
\end{tabular}


This is on a par with some Arabic dialects such as Moroccan, Egyptian and Kuwaiti spoken dialects as is shown by Aoun et al. (2010, p. 98). The difference being between laa and maa when hosting the subject clitics is that the former is only used in correlative constructions and can be followed by either non-verbal predicates or a perfective or imperfective verbal predicates, while the latter, in such a case, can only be followed by non-verbal predicates, i.e., AP, NP, PP but not a VP.

The other property of heads that may be seen on the negative variants of maa, i.e., muи and mee, is that they show gender agreement features where the former carries (or used to carry) masculine features and the latter carries feminine features. These variants can only be followed by non-verbal predicates. It then follows that the negative particles project in the head of NegP, namely $\mathrm{Neg}^{\circ}$ as represented in Figure 7.

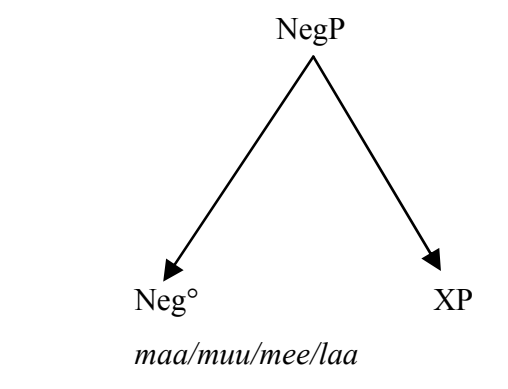

Figure 7. The negatives project in NegP.

Due to the fact that the prohibitive laa "don't" and the correlative structure laa "neither...nor" show different syntactic properties from the negative maa and its variants, and the fact that the negative particles muи and mee function almost the same, the author confines this study to the negative maa and its variants muu and mee. Notice that in all examples mеe can replace тии as long as the gender of the negated predicate is feminine. Now the paper moves on to explore the syntactic properties of the negative maa and its variants and how they interact with their predicates.

\section{Predicates and Negation}

The negative maa can precede a verb form, be it a lexical or functional, to negate the proposition expressed by the verbal predicate. Contrary to maa, the negatives maa and muи can only occur in non-verbal sentences to negate non-verbal predicates. Thus, both verbal and non-verbal predicates appear in the scope of negation. In other words, the hierarchical placement and choice of a HA negative varies according to the form and position of the negated element. The position of an XP may change from a clausal structure to another depending on some syntactic properties. For example, the Standard Arabic negatives lam and lan (generated in $\mathrm{NegP}$ ) are tensed and they move from $\mathrm{Neg}^{\circ}$ to $\mathrm{T}^{\circ}$. This is accounted for by the fact that lam negates the event in the past and lan negates the event in the future. Both negatives can only be followed by imperfective verb forms (Al Zahrani, 2008; Alharbi, 2000a; Ouhalla, 1988).

This shows evidence that negatives (NegP) interact with the functional category of Tense (TP) and AspP. Moreover, negatives are sensitive to the nature of the predicates that they precede, i.e., verbal or non-verbal. For example, the negative maa can only precede a perfective or imperfective verb form, including auxiliary and lexical verbs. The negative muи/mee can only precede non-verbal predicates, i.e., participial forms, verbal nouns, adjectival forms and nouns. Table 2 shows the negative particles and the Predicates that they can combine with. 
Table 2

Negatives and the Predicates That They Combine With

\begin{tabular}{|l|l|}
\hline NEGATIVES & PREDICATES \\
\hline maa & Perfective/Imperfective verb forms \\
\hline muu/mee & Non-verbal forms (Nouns, Adjectivals, and Participials) \\
\hline
\end{tabular}

The literature shows that the Arabic negative particle maa, irrespective of dialect, does not indicate tense (Al-Tamari, 2001; Alharbi, 2000a; Aoun et al., 2010; Benmamoun, 1992, 1996, 2000; Fassi, 1993; Ouhalla, 1991, 1993; Shlonsky, 1997). The author admits that this is also the case with the HA maa. However, the literature shows that linguists differ in their analysis of the placement of maa in other Arabic dialects, but none of these studies explores HA negatives. Some claim that maa is generated in NegP under TP (Aoun et al., 2010; Bahloul, 1996; Benmamoun, 1992, 1996, 2000; Ouhalla, 1994); ${ }^{2}$ while others claim that maa is generated in NegP above TP (Alharbi, 2000a; Fassi, 1993; Ouhalla, 1993; Shlonsky, 1997; Soltan, 2007). ${ }^{3}$

In this study, the author combines these two views in claiming that the scope of negation depends on the position of the negative particle and the negated element. The crucial difference between the author's analysis and the above mentioned theories is that they have analyzed negatives independently of the different predicates and their structure and constituents. The paper shows how negation may occur higher or lower than TP, depending on the form of the negative, the predicate it negates and the status of $\mathrm{T}^{\circ}$. The paper also shows that negative particles project in $\mathrm{NegP}$ and they must always be adjacent to the predicate they negate so that the negated element, be it a verb, auxiliary, or non-verbal predicate, adjoins to the negative in $\mathrm{Neg}^{\circ}$.

\section{Negation With Verbal Predicates}

Look at the example in (1) above repeated as (2) where tense can be in the scope of negation (NegP dominates TP).

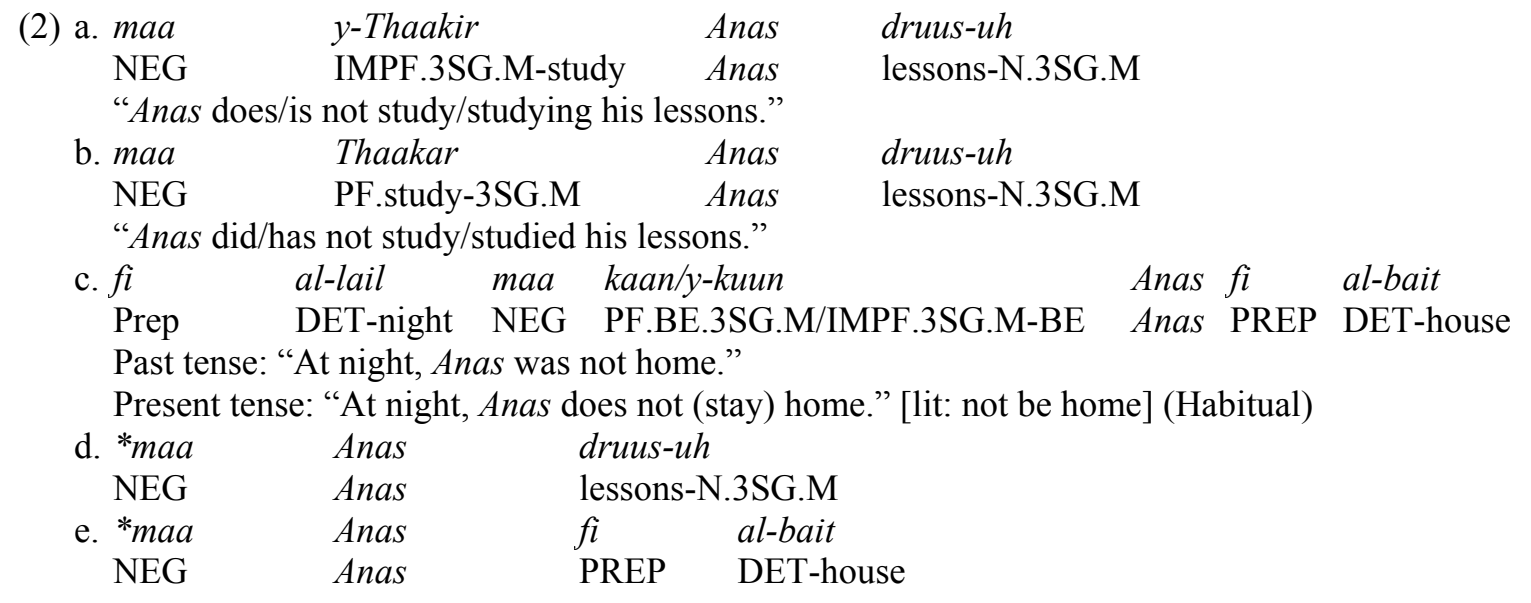

In (2), the proposition is negated. The negative maa is the only available negative because it is followed by verbal forms in $\mathrm{T}^{\circ} / \mathrm{Asp}^{\circ}$. The examples also show that the verb forms following the negative can be either an imperfective lexical verb (in $\mathrm{Asp}^{\circ}$ ) as in (2a), a perfective lexical verb (in $\mathrm{T}^{\circ}$ ) as in (2b) or a perfective/imperfective auxiliary verb (in $\left.\mathrm{T}^{\circ} / \mathrm{Asp}^{\circ}\right)$ as in $(2 \mathrm{c})$. Notice that $(2 \mathrm{c})$ contains the non-verbal predicate

\footnotetext{
${ }^{2}$ Benmamoun (2000) claims that maa is generated in Spec,NegP and that negation has one fixed position in Arabic. However, Aoun et al. (2010) argue that having one fixed projection for negatives does not account for all the facts.

${ }^{3}$ Ouhalla (1993, p. 288) argues that maa occupies the head of FP (Focus Projection) above TP.
} 
fi al-bait "at home", so in the present tense reading only the imperfective $y k u u n$ must project in Asp ${ }^{\circ}$, whereas only the perfective kaan must project in $\mathrm{T}^{\circ}$ in the past tense reading (see Al Zahrani, 2008, 2013). The absence of a verb form following maa renders the sentences ungrammatical as in (2d-e). This shows that the presence of the negative maa requires a verbal form in the head of TP or AspP, which in turn shows how the functional head of negation interacts with the functional heads of TP and AspP.

The examples in (2) demonstrate that the negatives are projected higher than TP and its internal structure (AspP, Tax-AspP, VP), providing evidence that when verbal forms are present NegP is external to TP and $\mathrm{NegP}$ has scope over the entire proposition. This is not always the case with non-verbal predicates as shown later in this paper.

Technically, the presence of either a perfective or imperfective verb form after the negative suggests the following syntactic properties. If perfective, then the verb has to merge with the $[+$ past $]$ abstract feature in $\mathrm{T}^{\circ}$ after checking off the taxis-aspect features in Tax-Asp ${ }^{\circ}$. If imperfective, the verb has to check the taxis-aspect features while its movement to $\mathrm{T}^{\circ}$ is not motivated. In short, the negative maa can select TP associated or unassociated with [+past] and thus may be immediately followed by a perfective or imperfective verb.

One more observation from the example in (2c) is that the perfective auxiliary kaan is generated in $\mathrm{T}^{\circ}$, and the negative maa occurs between the DP Anas and kaan. The DP Anas cannot occur between the auxiliary/lexical verb and the negative due to the incorporation between the verb and the negative maa in $\mathrm{Neg}^{\circ}$ as illustrated in the next section. If this is correct, the negative maa is external to TP in (2b).

\section{Incorporation in NegP}

This section shows that the negative particle forms a complex with its immediate following predicate. This complex cannot be separated by any element, including Subject/left-dislocated DPs. Alharbi (2000a, 2000b) argues that in Arabic, irrespective of dialect, NegP forces the head of its complement phrase (either verbal or non-verbal) to adjoin to the negator in $\mathrm{Neg}^{\circ}$. The author adopts Alharbi's (2000a) view and calls this adjoining of an element to the negative in Neg "incorporation" where one head is incorporated into another head. This is represented in (3).

(3) a. $\left[\mathrm{NegP}\left[\mathrm{Neg}^{\circ}\left[\mathrm{TP}\left[\mathrm{T}^{\circ}\right]\right]\right]\right]$

b. $\left[\mathrm{NegP}\left[\mathrm{Neg}^{\circ}-\mathrm{T}_{\mathbf{m}}^{\circ}[\mathrm{TP}[\mathrm{m}]]\right]\right]$

The schema in (3a) shows that NegP dominates TP. (3b) suggests that when NegP dominates TP, the element generated in (or has moved to) $\mathrm{T}^{\circ}$ must adjoin to the negator in $\mathrm{Neg}^{\circ}$, so both heads form the negative-verbal complex $\left[\mathrm{Neg}^{\circ}-\mathrm{T}^{\circ}\right]$; the Subject cannot intervene between the two heads. In this negative-verbal incorporation the negative negates the verb and its complement. In (3), the verb/auxiliary must move from Tax-Asp ${ }^{\circ} / \mathrm{Asp}^{\circ} / \mathrm{T}^{\circ}$ to adjoin to the negative in the head of NegP. This incorporation forms the negative-verb (lexical or functional) complex $\left[\mathrm{Neg}^{\circ}-\mathrm{T}^{\circ}\right]$, within which no elements can intervene. To illustrate this, observe the optional landing sites of Subject DP in an affirmative example as shown in (4b). Note that $(H)$ stands for the DP Hind.

(4) a. $f i$ al-lail t-kuun thaakir Hind druus-ha Prep DET-night IMPF.3SG.F-BE IMPF.3SG.F.study Hind lessons-N.3SG.F "At night, Hind studies her lessons."
b. $H_{4} \quad f i \quad$ al-lail $H_{3-4}$ t-kuun
$\mathrm{H}_{2} \quad$ t-Thaakir
$H_{1} \quad$ druus- $h a$
$H \quad$ Prep DET-night $H \quad$ IMPF.3SG.F-BE $H$ IMPF.3SG.F.study $H$ lessons-N.3SG.F
"Hind, she studies her lessons." (Topic reading with $H_{4}$ )
"Hind studies her lessons." (Other readings) 
In (4a), the subject Hind is in Spec,VP where it has absorbed the nominative case through the TP $>$ VP chain. Evidence for this claim comes from the positions of both the imperfective auxiliary $t$-kuun in $\mathrm{Asp}^{\circ}$ and the imperfective lexical verb $t$-Thaakir, which cannot move out of Tax-AspP to AspP since Asp ${ }^{\circ}$ is filled with the trace of the imperfective auxiliary. Example (4b) shows the optional landing sites for the DP Hind, represented as $(H)$. The DP $\left(H i n d_{1}\right)$ is in Spec,VP. It has overtly moved via Spec,Tax-AspP $\left(H i n d_{2}\right)$ to Spec,AspP $\left(\mathrm{Hind}_{3}\right)$ before landing in Spec,TP $\left(\mathrm{Hind}_{4}\right)$. These four optional landing positions are all internal to TP. The last option is an instance of left-dislocation where the DP $\left(H_{i n d} d_{5}\right)$ is base-generated higher than TP.

The Subject DP cannot occur within the negative complex of the negative and auxiliary t-kuun, as illustrated in (5).

(5) a. $f i$

maa-t-kuun

t-Thaakir

Hind druus-ha

Prep DET-night NEG-IMPF.3SG.F-BE IMPF.study-3SG.M Hind lessons-N.3SG.F

"At night, Hinddoes not study her lessons." (Habitual)

$\left[\operatorname{Prep}\left[\mathrm{NegP}^{\text {maa-tkuun }}{ }_{k}\left[\mathrm{TP}_{\mathrm{PRSk}}\left[\mathrm{AspP}_{\boldsymbol{k}}\left[\operatorname{Tax}-\mathrm{AspP}^{\text {t-Thaakir }}{ }_{t} \mathrm{VP}\left[\operatorname{Spec}^{\text {Hind }}\left[\mathrm{V}^{\mathrm{THKR}}{ }_{t}\left[\mathrm{DP}^{\text {druus-ha }}\right]\right]\right]\right]\right]\right]\right]\right]$

b. $\left(H_{5}\right) \mathrm{fi}$ al-lail $H_{4}$ maa-tkuun $H_{2-3}$ t-Thaakir $H_{1}$ druus-ha

$\mathrm{H}$ PREP DET-night H NEG-IMPF.3SG.F-BE H IMPF.3SG.M study H lessons-N.3SG.F

"Hind, at night, she does not study her lessons." (Topic reading with $H_{5}$ )

"Hind does not study her lessons."
c. *maa
Hind
$t$-kuun
t-Thaakir
druus-ha
NEG Hind
IMPF.3SG.F-BE
IMPF.3SG.F.study
lessons-N.3SG.F

In (5a), the imperfective auxiliary $t$-kuun, which is the head of the complement of the negative maa, has obligatorily moved from $\mathrm{Asp}^{\circ}$ via $\mathrm{T}^{\circ}$ to adjoin to maa in $\mathrm{Neg}^{\circ}$ while the subject Hind remains in situ as illustrated in Figure 8.

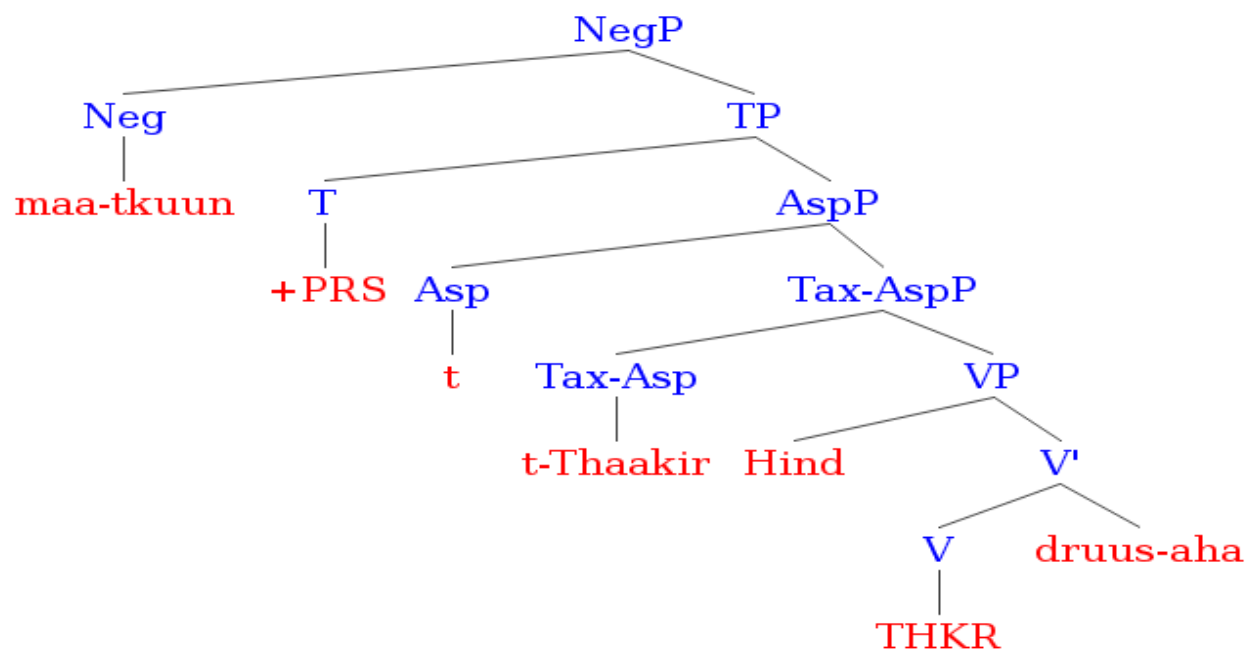

Figure 8. Auxiliary tkuun $\left(\mathrm{Asp}^{\circ}\right)$ adjoins to negative $m a a$ in $\mathrm{Neg}^{\circ}$ via $\mathrm{T}^{\circ}$.

Underlyingly, the root $\sqrt{T H K R}$ has moved to Tax-Asp ${ }^{\circ}$ to merge with the taxis-aspect features; the imperfective auxiliary $t$-kuun is base-generated in $\mathrm{Asp}^{\circ}$ and $\mathrm{T}^{\circ}$ is empty as the deictic tense is non-past (whether it is +PRS or +FUT depends on the interpretation). The imperfective auxiliary $t$-kuun must move to $\mathrm{Neg}^{\circ}$ via $\mathrm{T}^{\circ}$ to adjoin to the negative maa, while the subject remains in situ.

Example (5b) shows the further overt optional movement of the subject where it may move from Spec,VP $\left(H_{i n d}\right)$ to Spec,TP $\left.\left(H_{i n d}\right)_{4}\right)$ via Spec,Tax-AspP $\left(H i n d_{2}\right)$ and Spec,AspP $\left(H i n d_{3}\right)$. The left-dislocated DP $\left(H i n d_{5}\right)$ can only be base-generated higher than the inseparable negative complex [maa-t-kuun]. The presence of the DP 
Hind between the negative and the auxiliary renders (5c) ungrammatical.

It has been shown that the incorporation takes place between the negative and the imperfective auxiliary which is based generated in AspP. Now the paper shows how the incorporation can also take place between a negative and other perfective or imperfective lexical/auxiliary verb forms where the verb must move from its head position to $\mathrm{Neg}^{\circ}$. This negative-verb complex occurs higher than TP as shown in (6).
(6) a. maa-t-Thaakir
Hind
druus-ha
NEG-IMPF-3SG.F-study
Hind
lessons-N.3SG.F
"Hinddoes not study her lessons."
b. maa-kaan-at
t-Thaakir
Hind
druus-ha
NEG-PF.BE-3SG.F
IMPF.3SG.F-study
Hind
lessons-N.3SG.F
"Hind was not studying her lessons." "Hind did not use to study her lessons."

Example (6a) shows that the perfective verb $t$-Thaakir has moved from Tax-AspP to $\mathrm{T}^{\circ}$ (via AspP) before adjoining to the negative $m a a$ in $\mathrm{Neg}^{\circ}$. Note that imperfective verbs can only move from Tax-Asp ${ }^{\circ}$ to $\mathrm{Asp}^{\circ}$ if there is no auxiliary in $\mathrm{Asp}^{\circ}$ (see Chapters 5 and 6 in Al Zahrani, 2013). They cannot move to $\mathrm{T}^{\circ}$ because present time reading does not require phonological content in $\mathrm{T}^{\circ}$. There is no evidence for the movement of an imperfective verb into $\mathrm{T}^{\circ}$. This is not the case when NegP dominates TP and the verb form is imperfective as in (6a) where the presence of $\mathrm{NegP}$ forces the imperfective $t$-Thaakir to move from $\mathrm{Asp}^{\circ}$ into $\mathrm{T}^{\circ}$ and then adjoin to the negative $m a a$ in $\mathrm{Neg}^{\circ}$ as illustrated in Figure 9.

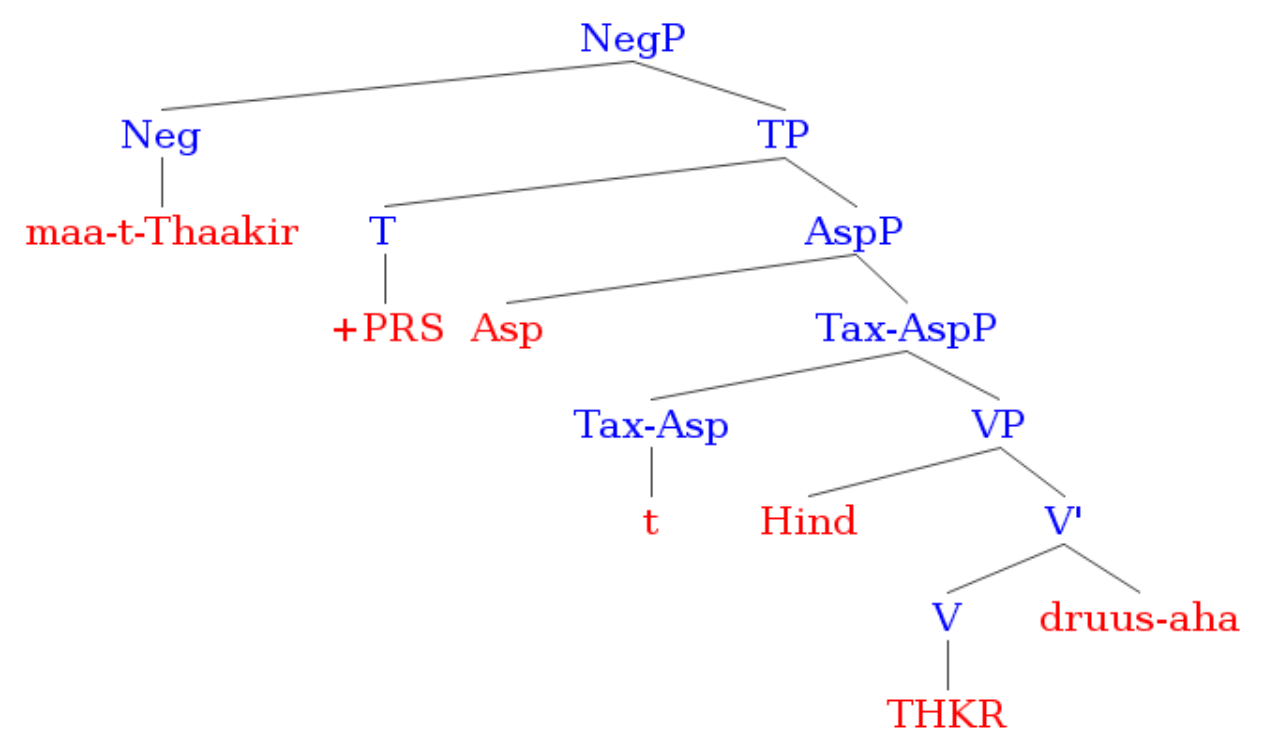

Figure 9. Lexical $t$-Thaakir adjoins to negative maa in $\mathrm{Neg}^{\circ}$ via $\mathrm{Tax}_{-} \mathrm{Asp}^{\circ}, \mathrm{Asp}^{\circ}$, and $\mathrm{T}^{\circ}$.

Similarly, (6b) shows that the presence of the negative maa forces the perfective auxiliary kaan-at, which is base generated $\mathrm{T}^{\circ}$, to move from $\mathrm{T}^{\circ}$ to $\mathrm{Neg}^{\circ}$ to form the negative verbal complex [maa-kaan-at] while the lexical verb stays in Tax-Asp ${ }^{\circ}$. While the subject Hind $(H)$ has not moved from Spec,VP in Figure 9, further overt optional movement can take place as shown in (7).
(7) a. $\left(H_{6}\right)$
bukrah
$\left(H_{5}\right)$
maa-t-Thaakir
$\left(H_{2-4}\right) \quad\left(H_{1}\right)$ druus-ha
Hind
tomorrow Hind NEG-IMPF.3SG.F-study
Hind Hind lessons-N.3SG.F
"Hind, tomorrow, she does not study her lessons." (Topic reading with $H_{6}$ )
"Tomorrow, Hind does not study her lessons."
b. *bukrah
maa-Hind-t-Thaakir
druus-ha
tomorrow
NEG-Hind-IMPF.3SG.F-study
lessons-N.3SG.F 
Example (7a) shows that the subject Hind can move overtly from Spec,VP (Hind $\left.)_{1}\right)$ to Spec,Tax-AspP $\left(\right.$ Hind $\left._{2}\right)$, Spec,AspP $\left(\right.$ Hind $\left._{3}\right)$ and Spec,TP $\left(\right.$ Hind $\left._{4}\right)$. Notice that the DP $\left(\right.$ Hind $\left._{4}\right)$ is in Spec,TP though in the surface structure it appears after the imperfective verb $t$-Thaakir due to the incorporation of the verb into $\mathrm{Neg}^{\circ}$. The subject Hind can also move to Spec,NegP $\left(\right.$ Hind $\left._{5}\right)$ but it cannot intervene between the negative particle maa and the imperfective t-Thaakir as shown by the ungrammaticality of (7b). While the presence of the subject external to TP is considered to be topicalized or left-dislocated, one may argue that the subject (Hind $\left.)_{5}\right)$ in (7a) has moved to Spec,NegP as it is permitted by the movement of the imperfective verb $t$-Thaakir from the head of TP to adjoin to the negator in the head of NegP, hence the movement of the subject Hind from Spec,TP to Spec,NegP. The DP $\left(\right.$ Hind $\left._{6}\right)$ is left-dislocated in the left periphery (Topic reading).

This section shows that negation interacts with tense and aspect. When NegP dominates TP, it forces the verb to move from $\mathrm{T}^{\circ}$ to adjoin to the negative in $\mathrm{Neg}^{\circ}$. This obligatory movement impacts on the distribution of imperfective aspect verbs such that an imperfective verb whether lexical or functional must move via the head of TP, even though they do not move in the absence of negation. This implies that a verb form is not allowed in $\mathrm{T}^{\circ}$ unless its feature is [+past] or it is triggered by the functional head NegP that is higher than TP. The next section explores negatives when they occur in non-verbal clauses.

\section{Negation With Non-verbal Predicates}

It is noteworthy to recall that the gender-based negatives namely, тии (masculine) and mee (feminine) can occur before the predicate Hilu "beautiful" in without the visibility of the auxiliary. The author argues that this is resulted by the fact that the gender-based negative particles have taken over the gender inflections with the absence of an overt verb that would otherwise take the inflection as shown on the auxiliary ykuun above.

In other words, the gender-based negatives carry some head properties as they show gender features. Therefore, the author has argued above that they are heads. However, they are variants of maa and the difference being between the negative maa and its variants тии and mee is that the former negative almost always subcategorizes for finite clauses while the latter negatives, i.e., the variants, always subcategorize for all other phrases, namely, NP, AP, and PP but not for VP.

It is worth recalling that the hierarchical representation for nominal sentences differs from the hierarchical structural for verbal sentences in that the former lacks the Tax-AspP and VP nodes while it contains the PredP node.

As in the case of verbal predicates, the negatives occur before the non-verbal predicates to have scope over the negated proposition. However, the position of the negatives varies according to the relative scope.

This section shows that TP and NegP may dominate each other. Recall that non-verbal clauses contain the functional categories of TP and AspP that can be filled with the perfective and imperfective auxiliary verb forms respectively. NegP may dominate PredP where both the negative head and the predicate head are dominated by TP and AspP respectively. With non-verbal predicates only the negative muи/mee, but never maa, can project into NegP that dominates PredP. Neg may also dominate TP, AspP and PredP respectively. In this case if tense is [+past], the perfective auxiliary kaan must project in $\mathrm{T}^{\circ}$; hence, only the negative maa can project in NegP to negate the entire proposition. If the tense is non-past, $\mathrm{Asp}^{\circ}$ may also be filled with $y$ kuun . These differences are illustrated in (8). 
(8) a. $\left.\quad\left[\operatorname{TP}_{\mathrm{PRS}}{ }^{\emptyset}\left[\mathrm{AspP}^{\emptyset}\left[\operatorname{PredP}^{\text {aljawwHilu }}\right]\right]\right]\right]$

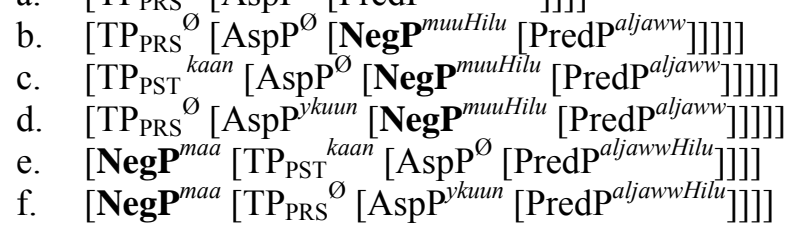

The schemata in (8) suggest different positions for NegP. While (8a) shows the affirmative structure for non-verbal clauses, $(8 \mathrm{~b})$ shows that if the predicate is non-verbal and tense is non-past, NegP projects lower than TP, but still dominates PredP. In this case, muu/mee is the only negative that can precede non-verbal predicates. Note that both heads of TP and AspP are empty. However, the auxiliary kaan/ykuun can project in $\mathrm{T}^{\circ} / \mathrm{Asp}^{\circ}$ as in (8c-d) respectively. In this latter case NegP scopes over the non-verbal predicate. If the predicate is non-verbal and tense is [+past] NegP may dominate TP and can only be occupied by maa. The incorporation in $\mathrm{Neg}^{\circ}$ must always take place, so when NegP is external to TP, the author proposes that the auxiliary moves via $\mathrm{T}^{\circ} / \mathrm{Asp}^{\circ}$ to adjoin to maa in NegP (8e-f). This implies that the auxiliary must move past TP. Non-verbal predicates in PredP must also adjoin to the negative particle in NegP that is lower than TP (8c). These representations are exemplified below.

Consider the examples in (9) where (9a) is affirmative while (9b) is negative and both the negative and the non-verbal predicate are incorporated in $\mathrm{Neg}^{\circ}$.

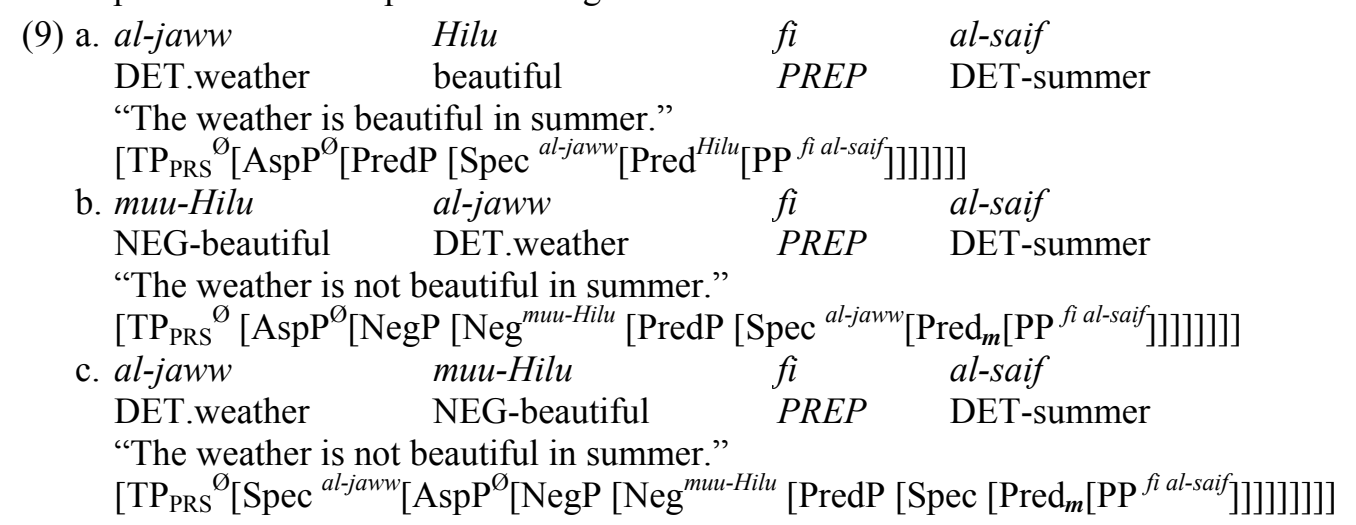

Example (9a) is affirmative where al-jaww is in Spec,PredP and the predicate Hilu "beautiful" is in Pred". Example (9b) shows that the negative muи can occur before the predicate Hilu without the visibility of the imperfective auxiliary. This suggests that both TP and AspP are empty and the tense is non-past. The non-verbal predicate must adjoin to the negative muи in $\mathrm{Neg}^{\circ}$. The subject DP al-jaww remains in situ and it gets its nominative case from the TP $>$ PredP chain (see Al Zahrani, 2013). Thus, the negative muи negates non-verbal predicates that are dominated by TP whose tense feature is unmarked and interpreted as present. While in (9b) the Subject DP has moved higher than the negative-predicate complex structure [muu-Hilu], it cannot separate the negative-predicate complex as shown by the ungrammaticality of (10).
(10) *muu-al-jaww-Hilu
NEG-weather-beautiful
fi al-saif
PREP DET-summer

The negative-predicate complex structure $\left[\right.$ mun-Hilu] does not merge with the tense in $\mathrm{T}^{\circ}$ as both NegP and PredP are lower than TP and NegP triggers its immediate following head, not preceding head, to adjoin to the negative in $\mathrm{Neg}^{\circ}$. Evidence for this claim comes from the fact that the subject al-jaww can move to Spec,NegP, which is between TP and $\mathrm{Neg}^{\circ}$, where it separates the negative complex from kaan as in (11a) (Cf. Schema (8c)); or it (the subject DP) can be left-dislocated to indicate a Topic reading as in (11b). Note that in 
both examples the negative and the auxiliary are not incorporated in $\mathrm{Neg}^{\circ}$.
(11) a. kaan
al-jaww
muи-Hilu
fi
PF.BE-3SG.M
DET-weather NEG-beautiful
PREP
al-saif
"The weather was not beautiful in summer."
$\left[\mathrm{TP}_{\mathrm{PST}}{ }^{{ }^{2 a a n}}\left[\mathrm{AspP}^{\varnothing}\left[\mathrm{NegP}\left[\operatorname{Spec}^{{ }^{\text {al-jaww }}}\left[\mathrm{Neg}^{\text {mun-Hilu }} \mathbf{m}\left[\operatorname{PredP}\left[\operatorname{Pred}_{\mathbf{m}}\left[\mathrm{PP}^{\text {fi al-saiaf }}\right]\right]\right]\right]\right]\right]\right]\right.$
b. al-jaww kaan muu-Hilu fi al-saif
DET-weather PF.BE-3SG.M NEG-beautiful PREP DET-summer
"The weather, it was not beautiful in summer."
$\left[\right.$ Topic $^{\text {al-jaww }}\left[\mathrm{TP}_{\mathrm{PST}}{ }^{\text {kaan }}\left[\mathrm{AspP}^{\varnothing}\left[\mathrm{NegP}{ }^{\text {mun-Hilu }}{ }_{\mathbf{m}}\left[\operatorname{PredP}_{\text {[Pred }}\right.\right.\right.\right.$ [PP $\left.\left.\left.\left.\left.\left.\left.^{\text {fi al-saiaf }}\right]\right]\right]\right]\right]\right]\right]$
c. al-jaww y-kuun muu-Hilu fi al-saif
DET-weather IMPF.3SG.M- NEG-beautiful PREP DET-summer
$\mathrm{BE}$
"The weather is not beautiful in summer."

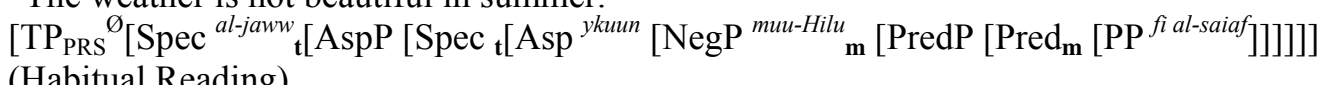
(Habitual Reading)

Interestingly, the examples in (11) show that the scope of negation differs according to the syntactic position of NegP. One can observe that in (11) NegP only dominates the PredP and the PP while it is dominated by both TP and AspP that can be filled with the auxiliary verbs (Cf. Schemata (8c-d)). Now the paper shows how NegP may dominate both TP and AspP that can be filled with auxiliary verb forms.
(12) a. al-jaww maa-kaan
Hilu
DET-weather
NEG-PF.BE.3SG.M beautifu
$f i$
PREP
al-saif
"The weather was not beautiful in summer."
$\left[\mathrm{NegP}\left[\operatorname{Spec}^{\text {al-jaww }}\left[\mathrm{Neg}^{\text {maa-kaan }}{ }_{\mathbf{k}}\left[\mathrm{T}_{\mathrm{PSTk}}\left[\operatorname{AspP}^{\varnothing}\left[\operatorname{PredP}^{\text {Hilu }}\left[\mathrm{PP}^{\text {fial-saiaf }}\right]\right]\right]\right]\right]\right]\right]$
$\begin{array}{lllll}\text { b. al-jaww } & \text { maa-y-kuun } & \text { Hilu } & f i & \text { al-saif } \\ \text { DET-weather } & \text { NEG-IMPF.3SG.M-BE } & \text { beautiful } & \text { PREP } & \text { DET-summer }\end{array}$
"The weather is not (does not become) beautiful in summer."
$\left[\mathrm{NegP}\left[\operatorname{Spec}^{\text {al-jaww }}\left[\mathrm{Neg}^{\text {maa-ykuun }}{ }_{\mathbf{k}}\left[\mathrm{T}_{\mathbf{k}}^{\varnothing}\left[\operatorname{AspP}_{\mathbf{k}}\left[\operatorname{PredP}^{\text {Hilu }}\left[\mathrm{PP}^{\text {fi al-saiaf }}\right]\right]\right]\right]\right]\right]\right]$

The examples in (12) demonstrate that negation can occur before an auxiliary verb form that is followed by a non-verbal predicate where $\mathrm{Neg}^{\circ}$ can only be filled with maa. In such a case the auxiliary must move past TP to adjoin to maa in the head of NegP. The Subject DP can move from its base position to higher Specifiers without intervening between the inseparable elements of the negative-auxiliary complex. This in turn suggests that NegP does not have one fixed position but it occupies different positions in the hierarchy depending on the relative scope.

Examples (11) and (12) demonstrate that when negation scopes over PredP, NegP occurs lower than TP and consequently it does not merge with tense in $\mathrm{T}^{\circ}$ because the latter is higher than the negative element. When negation scopes over TP, NegP occurs higher than TP, AspP and PredP and it triggers the perfective auxiliary in past time reading to adjoin to the negative in $\mathrm{Neg}^{\circ}$. The auxiliary verb in Asp ${ }^{\circ}$ moves and adjoins to $\mathrm{maa}$ in $\mathrm{Neg}^{\circ}$. In short, wherever a negative particle projects in $\mathrm{Neg}^{\circ}$ it triggers its following element, be it an auxiliary verb or a non-verbal predicate, to adjoin to it in the head of NegP; no matter how close or far the position of this element from $\mathrm{Neg}^{\circ}$ it must incorporate with the negative and form an inseparable negative complex. The Subject DP can freely move from its base position (Spec,PredP) to all higher Specifiers without breaking the negative complex.

\section{Conclusions and Recommendations}

What the author aimed to achieve in this study is a deeper understanding of the interplay between the morphosyntactic properties of some HA negative particles which negate a predicate and how these negatives 
interact with the categories of tense and aspect.

Negatives are generated in $\mathrm{NegP}$ and they may have scope over verbal and non-verbal predicates. NegP can be either higher or lower than TP depending on its scope, i.e., whether or not it scopes over the functional heads of TP and AspP, the lexical heads of Tax-AspP and VP or the predicate head of PredP. When NegP has wide scope it negates the entire proposition, whereas when it has narrow scope it negates the predicate expressed by either a lexical verb, an auxiliary verb or a non-verbal predicate. This in turn determines the form of the negative particle (maa or muи/mee). Hence, NegP occurs in a range of positions depending on the relative scope. NegP also triggers the head of the negated element to move from its base position to adjoin to the negative particle in $\mathrm{Neg}^{\circ}$. Consequently, this incorporation between the negative particle and the head of the negated element creates an inseparable negative complex that cannot be intervened by any other elements including the Subject DP, which can move from its base position (Spec VP/PredP) to higher Specifiers without breaking this negative complex. This paper also shows the interactions between the functional heads of tense, aspect, and negation. Investigating the semantic properties of the different negative positions with respect to the functional heads and the lexical/predicate head is left for future studies.

\section{References}

Abney, S. P. (1987). The English noun phrase in its sentential aspect (Doctoral dissertation). MIT, Cambridge, Mass.

Al Zahrani, M. (2008). Morphology of negation in modern Standard Arabic and spoken Hijazi Arabic (Master's thesis). University of Queensland, Brisbane.

Al Zahrani, M. (2013). Morphosyntactic and semanitc properties of Hijzai Arabic modals (Unpublished doctoral dissertation). University of Queensland, Brisbane, Australia.

Al-Barakati, A. (1984). Al-Nahw wa Al-Sarf Bain Al-Tamimyeen wa Al-Hijazyeen (Syntax and morphology between Tamimi people and Hijazi people). Makkah: AlFaisaliyah.

Alharbi, A. (2000a). The NEG elements in clausal structures. Syntaxis, 3.

Alharbi, A. (2000b). Verbal modals. majalat alAuluum alinsanyyah of Umm AlQura, 14, 1-36.

Al-Tamari, E. A. (2001). Sentential negation in English and Arabic: A minimalist approach (Doctoral dissertation). University of Kansas, Ann Arbor, Michigan.

Aoun, J., Choueiri, L., \& Benmamoun, E. (2010). The syntax of Arabic. New York: Cambridge University Press.

Bahloul, M. (1994). The syntax and semantics of taxis, aspect, tense and modality in Standard Arabic (Unpublished doctoral dissertation). Cornell University, New York.

Bahloul, M. (1996). Extending the negative phrase hypothesis: Evidence from Standard Arabic. In M. Eid (Ed.), Perspectives on Arabic linguistics, VIII (pp. 31-46). Amsterdam and Philadelphia: John Benjamins.

Bahloul, M. (2008). Structure and function of the Arabic verb. London: Routledge.

Benmamoun, E. (1992). Inflectional and functional morphology: Problems of projection, representation and derivation (Doctoral dissertation). University of Southern California, Los Angeles.

Benmamoun, E. (1996). Negative polarity and presupposition in Arabic. Perspectives on Arabic Linguistics, 8, 47-66.

Benmamoun, E. (2000). The feature structure of functional categories: A comparative study of Arabic dialects. New York: Oxford University Press.

Chomsky, N. (1980). On binding. Linguistic Inquiry, 11, 1-46.

Chomsky, N. (1994). Bare phrase structure. Cambridge, MA: Distributed by MIT Working Papers in Linguistics.

Chomsky, N. (1995). The minimalist program. Cambridge, Mass.: The MIT Press.

Fassi, A. (1993). Issues in the structure of Arabic clauses and words. Dordrecht, Boston, London: Kluwer Academic Publisher.

Fassi, A. (2012). Key features and parameters in Arabic grammar. Amsterdam: John Benjamins Publishing Company.

Ibn Qutaibah, M. (1970). Al-Ma'aarif. In T. Okashah (Ed.), Ihyaa 'luum alturaath al'arabi (Revitalizing the Arab heritage) (2nd ed.). Beirut: Dar iHyaa Al-Turath Al'arabi.

Koopman, H., \& Sportiche, D. (1991). The positions of subjects. Lingua, (85), 211-258.

Kremers, J. M. (2003). The Arabic noun phrase: Aminimalist approach (Doctoral dissertation). University of Nijmegen, LOT, The Netherlands. 
Margaret, O. (1975). Saudi Arabic urban Hijazi dialect basic course. Washington, DC: Foreign Service Institute.

Masanori, N. (1992). Move $\alpha$, scope and relativized minimality (Unpublished doctoral dissertation). McGill University, Montreal.

Mohammad, M. A. (1989). The sentential structure of Arabic (Doctoral dissertation). University of Southern California Library, Los Angeles, Calif.

Ouhalla, J. (1988). The syntax of head movement: A study of Berber (Doctoral dissertation). UCL, London.

Ouhalla, J. (1991). Functional categories and parametric variation. London: Routledge.

Ouhalla, J. (1993). Negation, focus and tense: The arabic laa and maa. Rivisita di Linguistica, 5.

Ouhalla, J. (1994). Verb movement and word order in SA. In D. Lightfoot \& N. Hornstein (Eds.), Verb movement (pp. 41-72). Cambridge: University of Cambridge Press.

Radford, A. (1997a). Syntactic theory and the structure of English: A minimalist approach. Cambridge: Cambridge University Press.

Radford, A. (1997b). Syntax: A minimalist introduction. Cambridge [England], New York: Cambridge University Press.

Shlonsky, U. (1997). Clause structure and word order in Hebrew and Arabic: An essay in comparative semitic syntax. New York: Oxford University Press.

Sieny, M. (1978). The syntax of urban Hijazi Arabic. London: Longman.

Soltan, O. (2007). On formal feature licensing in minimalism: Aspects of Standard Arabic morphosyntax (Unpublished doctoral dissertation). University of Maryland, College Park.

Speas, M. J. (1986). Adjuncts and projections in syntax (Unpublished doctoral dissertation). Massachusetts Institute of Technology, Cambridge, United States.

Szabolcsi, A. (1983). The possessor that ran away from home. The Linguistic Review, 3, 89-102.

Travis, L. (1984). Parameters and effects of word order variation (Doctoral dissertation). MIT, Mass. 